\title{
INVESTIGATION OF THE TEMPORAL CHANGE OF THE SOURCES OF AEOLIAN DUST DELIVERED TO EAST ASIA USING ELECTRON SPIN RESONANCE SIGNALS IN QUARTZ
}

\author{
YUYA YAMAMOTO ${ }^{1}$, SHIN TOYODA ${ }^{1}$, KANA NAGASIMA ${ }^{2}$, YASUHITO IGARASHI ${ }^{3}$ and RYUJI TADA ${ }^{4}$ \\ ${ }^{1}$ Okayama University of Science, 1-1 ridaichou Okayama, Japan \\ ${ }^{2}$ Japan Agency for Marine-Earth Science and Technology, Yokohama Kanagawa, Japan \\ ${ }^{3}$ Metrological Research Institute, Nagamine Tukuba Ibaraki, Japan \\ ${ }^{4}$ The University of Tokyo, Hongou Bunkyouku Tokyo, Japan
}

Received 10 February 2013

Accepted 28 June 2013

\begin{abstract}
The temporal change in the number of oxygen vacancies in quartz was investigated by observing the E1' center in the atmospheric depositions collected at two cities in Japan in the recent past. The depositions collected at Fukuoka in March show the ESR intensities being correlated with the sum of the number of the days, in the month, on which Kosa was observed while no such correlation was found in the deposition those collected at Akita but a trend of decrease with time. The present results suggest that the number of oxygen vacancies in quartz might be useful to estimate quantitatively the contribution of the dust originated from China to the atmospheric deposition in Japan.
\end{abstract}

Keywords: ESR, Kosa.

\section{INTRODUCTION}

The $\mathrm{E}_{1}$ ' center is one of the major paramagnetic lattice defects in crystalline quartz, which is an unpaired electron at an oxygen vacancy (Feigl et al., 1974). Unlike other impurity centers, it is known that the intensity of the $\mathrm{E}_{1}$ ' center increases on heating (Weeks and Nelson, 1960), due to an electronic process in quartz that electronic holes are transferred on heating to neutral oxygen vacancies with two electrons ( $\mathrm{Si}-\mathrm{Si}$ bond) to recombine one of the two electrons to form the $\mathrm{E}_{1}$ ' center (Jani et al., 1983). Based on this nature of the $\mathrm{E}_{1}$ ' center, it was proposed that the relative number of oxygen vacancies is obtained by measuring the signal intensity of the $E_{1}$ ' center after gamma ray irradiation to more than 200 Gy

Corresponding author: Y. Yamamoto

e-mail: s10rd04yy@std.ous.ac.jp followed by heating at $300^{\circ} \mathrm{C}$ for 15 minutes (Toyoda and Ikeya, 1991; Toyoda and Hattori, 2000).

For granitic quartz, this heat treated $\mathrm{E}_{1}$ ' center, indicative of the number of oxygen vacancies in quartz, was found to be correlated with the ages of the host granites (Toyoda and Hattori, 2000). This observation implies that oxygen vacancies are created in natural quartz by some natural radiation. Toyoda (2005) showed that external gamma and beta rays from the minerals surrounding quartz creates the oxygen vacancies.

The number of oxygen vacancies in quartz was further found to be useful in investigating the source of aeolian dust in the past. Toyoda and Naruse (2002) showed that the numbers of oxygen vacancies in quartz in aeolian dust accumulated in loess sequences formed in northern Japan in MIS 2 are systematically larger than those in southern Japan in MIS 2 and in both regions in MIS 1, latter values 
being consistent with those in Chinese loess plateau. They argued that there was significant contribution of dust to northern Japan in MIS 2 from a source with ages older than the source which contributes to Chinese loess plateau, most probably those from north eastern Siberia where basement rocks are Precambrian.

Nagashima et al. (2007) further investigated the dust contributions to sediments in core samples taken in Sea of Japan using the $\mathrm{E}_{1}$ ' center signal intensities (number of oxygen vacancies) and crystallinity indexes of quartz, based on the difference in those values, where the number of oxygen vacancies ranges from 4.5 to 9.6 for fine grain sediments in Taklimakan desert and from 12.3 to 16.6 for Mongolian Gobi desert (Sun et al., 2007). They found that the contribution from Taklimakan desert had been higher in warmer period and that from Mongolian Gobi desert in colder period during the last $150 \mathrm{ka}$.

At the beginning of spring, originated in dust storms in arid areas of China, fine grain air borne dust particles are brought to Japan by the westerly wind, which are observable by the eye. The sky turns yellowish brown due to the dust particles, being called Kosa (yellow sand). Observable amount of dust particles is sometimes deposited in living areas. It is known that many of the dust particles originated in the Mongolian Gobi desert as shown by the back trajectory analysis (Sugimoto et al. 2002). However, quantitative analysis for the temporal variation of transportation of the dust from China to Japan has not been done to date. In the present study, the temporal change in the number of oxygen vacancies in quartz was investigated in atmospheric depositions collected at two cities in Japan in the recent past of 50 years. It is shown that the ESR (electron spin resonance) intensity of the heat treated $\mathrm{E}_{1}$ ' center in quartz would be a useful proxy in discussing quantitatively the contribution of Chinese dust component in the atmospheric depositions.

\section{EXPERIMENTAL PROCEDURE}

The samples of atmospheric deposition (total deposition $=$ wet + dry) were collected for a month in a $0.5 \mathrm{~m}^{2}$ plastic open surface collector installed in the observation field of the meteoritic observatories at Fukuoka and at Akita (Fig. 1). The collected samples in the container were heated to evaporate out the water. Meteorological Research Institute offered the atmospheric depositions collected in March and in June in 1964 to 2000 for the present study. Samples of fine grain river sediment were also collected at Fukuoka as Fig. 2a and at Akita as Fig. 2b which would represent possible local dust sources.

About $150 \mathrm{mg}$ of each sample was treated with $50 \mathrm{ml}$ acetic acid of $20 \%$ for 8 hours to remove carbonate, and then soaked in a mixed solution of $40 \mathrm{ml}$ sodium citrate $\left(\mathrm{Na}_{3} \mathrm{C}_{6} \mathrm{H}_{5} \mathrm{O}_{7}\right)$ at the concentration of $0.3 \mathrm{~mol} / 1,5 \mathrm{ml} \mathrm{Na}$ $\mathrm{HCO}_{3}$ at the concentration of $1 \mathrm{~mol} / 1$, and $3 \mathrm{~g}$ of hydrosulfide sodium $\left(\mathrm{Na}_{2} \mathrm{~S}_{2} \mathrm{O}_{4}\right)$ at $80^{\circ} \mathrm{C}$ for 8 hours to remove iron and magnesium oxides. Subsequently, the sample was treated with $20 \%$ solution of hydrogen peroxide $\left(\mathrm{H}_{2} \mathrm{O}_{2}\right)$ heated at $60^{\circ} \mathrm{C}$ for 8 hours to remove organic matter. Finally, the sample was treated with hexafluorosilicic acid $\left(\mathrm{H}_{2} \mathrm{SiF}_{6}\right)$ for 1 week to remove feldspars. After rinsing, a fine grain size fraction less than $16 \mu \mathrm{m}$ was extracted using the Stoke's law.

ESR signals in the samples were observed with an ESR spectrometer, JEOL JES-PX2300 at Okayama University of Science. The signal intensity of the $E_{1}$ ' center was measured after gamma ray irradiation to $2.5 \mathrm{~Gy}$ and heating at $300^{\circ} \mathrm{C}$ for $15 \mathrm{~min}$ to measure the number of oxygen vacancies (Toyoda and Hattori, 2000). The measurement was performed at room temperature atconditions as follows; a microwave power of $0.01 \mathrm{~mW}$, a magnetic field modulation frequency of $100 \mathrm{kHz}$, its amplitude of $0.1 \mathrm{mT}$, a center field of $336.0 \mathrm{mT}$, a sweep range of $5 \mathrm{mT}$, a scan time of $30 \mathrm{~s}$, a time constant of $0.03 \mathrm{~s}$. The ESR signal intensity of the $\mathrm{E}_{1}$ ' center in quartz is expressed in a spin unit where one spin unit is equivalent to $1.3 \times 10^{15} \mathrm{spin} / \mathrm{g}$ (Toyoda and Naruse, 2002) after dividing the value by the sample mass and the quartz content obtained as described below.

The chemical treatment aimed to extract pure quartz from the samples, but it was not possible due to clay minerals in the sample. The quartz content in the sample after the chemical treatment was determined by the XRD analysis using the internal standard method with silicon (Klug and Alexander, 1974) where the content of quartz was obtained from the ratio of XRD park areas at $20.9^{\circ}$ of quartz and the one at $28.4^{\circ}$ of silicon in sample with

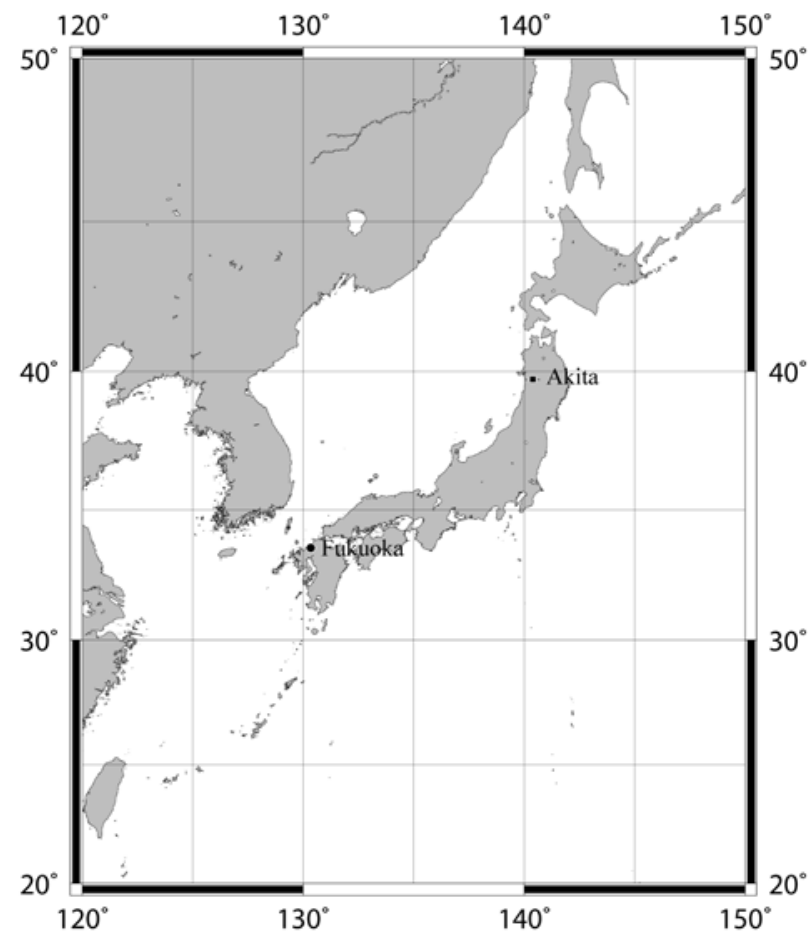

Fig. 1. Locations of Fukuoka and Akita where the sample of atmospheric deposition were collected. 
a
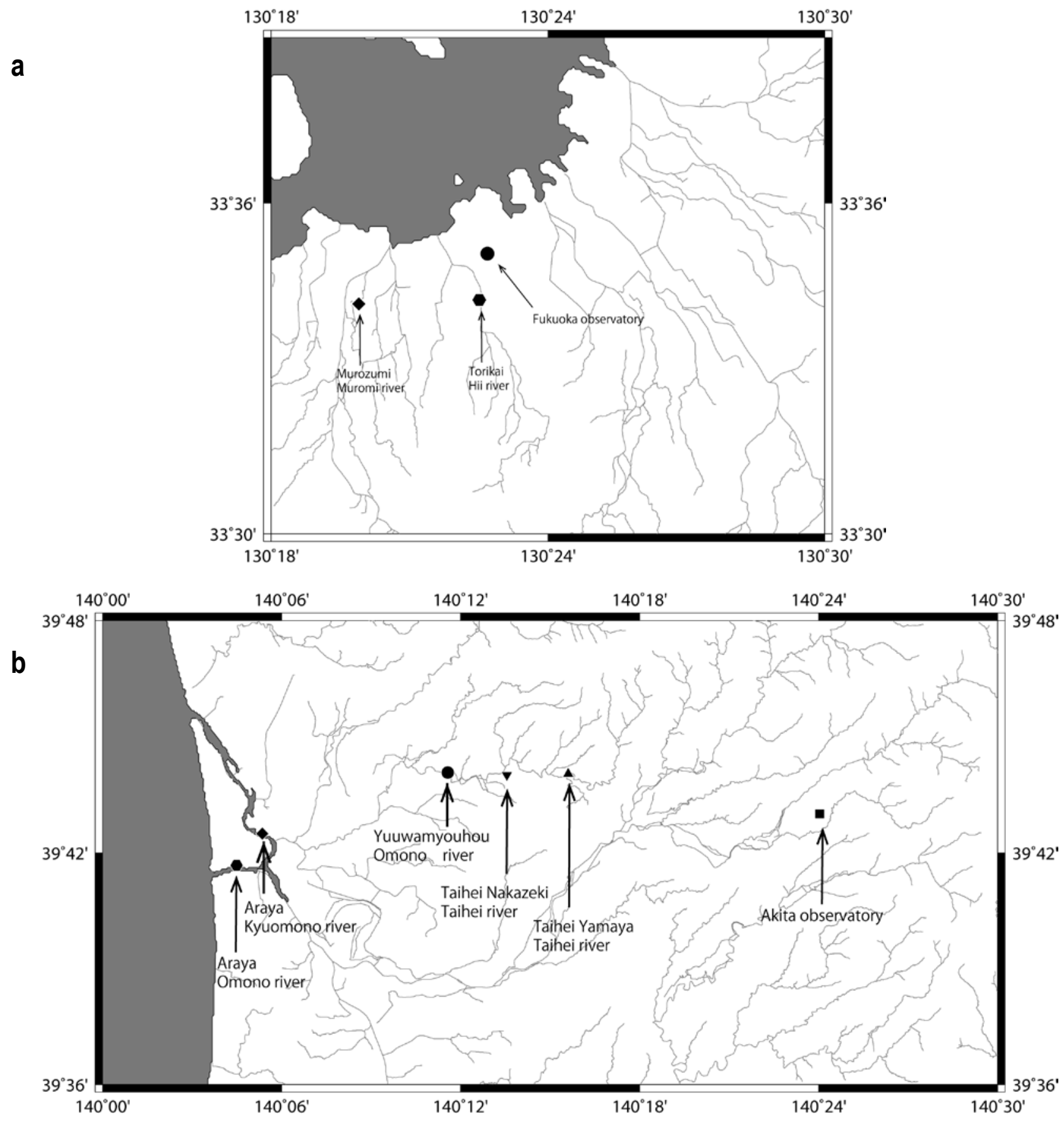

Fig. 2. Sampling locations (a) at Fukuoka and (b) at Akita for river sediments and the locations of observatories where atmospheric deposition were collected.

known amount of silicon, typically $10 \%$ of total mass. The XRD analysis was performed by using the PANalytical X' Part Pro X-ray diffractometer with a tube voltage of $45 \mathrm{kV}$ and a tube current of $40 \mathrm{~mA}$ at the University of Tokyo. The obtained quartz contents were typically $20 \%$ to $40 \%$.

\section{RESULTS AND DISCUSSIONS}

The temporal variation in the number of oxygen vacancies in quartz were obtained as shown in Figs. 3a to 3d for the depositions in March at Fukuoka, in June at Fukuoka, in March at Akita, and in June at Akita, respec 

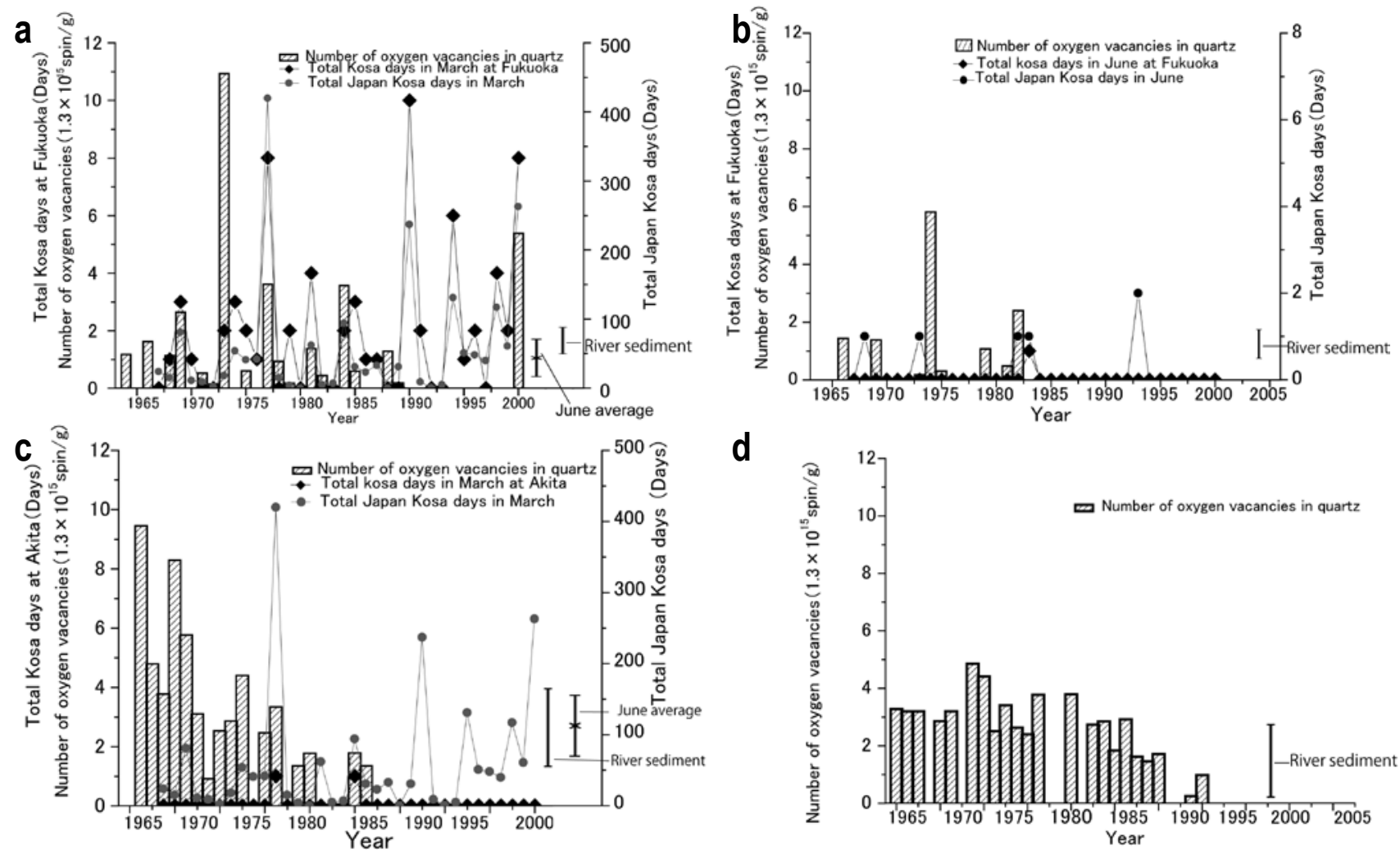

Fig. 3. Temporal change of oxygen vacancies in quartz extracted from atmospheric depositions and the total Kosa days (a) in March at Fukuoka, (b) in June at Fukuoka (c) in March at Akita and (d) in June at Akita.

tively. The numbers of the days on which Kosa was observed in the month, summed for all 123 observatories in Japan (total Japan Kosa days) (Japan Meteorological Agency http://www.jma.go.jp/jma/indexe.html) are also shown in Fig. 3a to 3d together with the numbers of the days on which Kosa was observed in the month in the city (total Kosa days). For the years with ESR no data in Fig. 3, ESR measurements were not possible because the amount of quartz was not sufficient. The number of oxygen vacancies observed in quartz extracted from river sediments collected at Fukuoka and at Akita are shown in Table 1.

The number of oxygen vacancies in quartz of atmospheric deposition collected at Fukuoka in March shows several peaks in the temporal change as in Fig. 3a. Most of those peaks match the peaks of the total Japan Kosa days (years 1969, 1973, 1977, 1984, 2000) and also those of the total Kosa days in Fukuoka. The numbers of total Japan Kosa days are almost proportional to that in Fukuoka meaning that the total Japan Kosa days are controlled by the Kosa days in western Japan.

Except for a high value in 1974, the average value for Fukuoka in June (Fig. 3b) is $1.04 \pm 0.79$, being consistent with the values for the river sediments. Considering that Kosa events were rarely observed in June as shown in Fig. 3b, main component of the atmospheric deposition in June would be originated in local sediment. Where the values observed in June would be considered as the "background", the values observed in March at Fukuoka, exceeding this "background", would have contribution from the source with higher oxygen vacancies which is correlated with the peaks in total Kosa days (Fig. 3a). As satellite images revealed that Kosa events are originated in dust storms in arid areas in China, this source can most probably be dust originated in China. This interpretation

Table 1. The number of oxygen vacancies observed quartz extracted from river sediment.

\begin{tabular}{lc}
\hline Location & $\begin{array}{c}\text { The number of oxygen } \\
\text { vacancies (spin unit) }\end{array}$ \\
\hline Akita & 1.32 \\
Yuuwamyouhou Omono river & 0.36 \\
Araya Omono river & 1.03 \\
Araya Kyuomono river & 3.07 \\
Taihei Nakazeki Taihei river & 1.89 \\
$\quad$ Taihei Yamaya Taihei river & \\
& $1.53 \pm 1.02$ \\
Average & \\
& \\
Fukuoka & 2.02 \\
$\quad$ Muromi river & 1.09 \\
Hii river &
\end{tabular}


is consistent with the previous observation that the number of oxygen vacancies in quartz in fine grain silt has high values, for example, 12.3 to 16.6 in the Mongolian Gobi desert (Sun et al., 2007).

At Akita, the values in March showed gradual decrease with time (Fig. 3c), having no correlation with total Kosa days. Average value for Akita in June, $2.72 \pm 1.09$, is in the range of those of local river sediments, $1.53 \pm 1.02$ (Table 1), indicating that the dust in June is again mostly originated in local sediment. If this value in June is considered to be the "background", the values in March exceeding this "background" would indicate the contribution from dust originated in China. However, not like at Fukuoka, those high values do not correlate with Kosa days because Kosa has seldom been observed at Akita, only one day in 1977 and in 1984, none in June.

As shown in Fig. 3c, in March, the number of oxygen vacancies, hence, the contribution of dust originated in China gradually decreased. This might correspond to the gradual temporal decrease of spring dust storm frequency in northern China (Zhu et al., 2008). The difference between Fukuoka and Akita in temporal change of the oxygen vacancies in quartz of atmospheric depositions might indicate that the mode of transportation of the dust from China to Japan is different depending on the location within Japan. At Fukuoka, contribution of the dust originated in China is controlled by episodic Kosa events in the specific years. On the other hand, at Akita, it is controlled by more averaged dust "reservoir". Transportation from that "reservoir" is not witnessed by eye, maybe because it is much diluted, but is detected by ESR as the number of oxygen vacancies in quartz.

When we assume the end members, the concentrations of oxygen vacancies in quartz, in the dust originated in China and in the local background, quantitative argument in the contribution is possible. If the source of the dust originated in China is assumed to be Mongolian Gobi as estimated by the back trajectory analysis (Sugimoto et al., 2002), the number of oxygen vacancy should be 12.3 to 16.6 (Sun et al., 2007), the present observed value indicate the contribution of the component of Mongolian Gobi in the atmospheric deposition. When the local end member value is assumed to be 3.62, which is average of the deposition in March, the value 4.40 (year 1974) corresponds to the contribution of $22 \%$ of Gobi component, and the value 8.29 (year 1968) to $52 \%$.

\section{SUMMARY}

The temporal changes in the number of oxygen vacancies in quartz of atmospheric depositions collected at Akita and at Fukuoka were investigated. The temporal change of the number in the sample collected at Fukuoka in March is correlated with the total Kosa days, while no correlation was found in Akita but gradual decrease with age. The number of oxygen vacancies in quartz in the atmospheric deposition might be an indicator to estimate quantitatively the contribution of the dust originated from China to the atmospheric deposition. The difference between Fukuoka and Akita would imply possible difference in mode of transportation of the dust to these two cities.

\section{REFERENCES}

Feigl FJ, Fowler WB and Yip KL, 1974. Oxygen vacancy model for the $\mathrm{E}_{1}$ ' center in $\mathrm{SiO}_{2}$. Solid State Communications 14(3): 225-229, DOI 10.1016/0038-1098(74)90840-0.

Japan Meteorological Agency, http://www.jma.go.jp/jma/indexe.html.

Jani MG, Bossoli RB and Halliburton LE, 1983. Further characterization of the $\mathrm{E}_{1}$ ' center in crystalline $\mathrm{SiO}_{2}$. Physical Review $B$ 27(4): 2285-2293, DOI 10.1103/PhysRevB.27.2285.

Klug HP and Alexander LE, 1974. X-Ray Diffraction Procedure, 2nd ed., 966p. John Wiley, Hoboken, NJ, USA.

Nagashima K, Tada R, Tani A, Toyoda S, Sun Y and Isozaki Y, 2007. Contribution of Aeolian dust in Japan Sea sediments estimated from ESR signal intensity and crystallinity of quartz. Geochemistry, Geophysics, Geosystems 8: Q02Q04, DOI 10.1029/2006GC001364.

Sugimoto N, Shimizu A, Matsui I, Uno I, Arao K and Chen Y, 2002. Movement of Kosa revealed continuous operation polarized rider network (Japanese title translated). Terrestrial Environments (Chikyu Kankyo) 7(2): 197-207 (in Japanese).

Sun Y, Tada R, Chen J, Chen H, Toyoda S, Tani A, Isozaki Y, Nagashima K, Hasegawa $\mathrm{H}$ and Ji J, 2007. Distinguishing the sources of Asian dust based on electron spin resonance signal intensity and crystallinity of quarts. Atmospheric Environment 41(38): 85378548, DOI 10.1016/j.atmosenv.2007.07.014.

Toyoda S, 2005. Formation and decay of the $\mathrm{E}_{1}$ ' center and its precursor in natural quartz: basics and applications. Applied Radiation and Isotopes 62(2): 325-330, DOI 10.1016/j.apradiso.2004.08.014.

Toyoda S and Hattori W, 2000. Formation and decay of the $\mathrm{E}_{1}$ ' center and of its precursor. Applied Radiation and Isotopes 52(5): 13511356, DOI 10.1016/S0969-8043(00)00094-4.

Toyoda S and Ikeya M, 1991. Thermal stabilities of paramagnetic defect and impurity centers in quartz: Basis for the ESR dating of thermal history. Geochemical Journal 25: 437-445.

Toyoda S and Naruse T, 2002. Eolian dust from the Asian deserts to Japanese Islands since the lost Glacial Maximum; the basis for the ESR method. Transactions, Japanese Geomorphological Union 23: 811-820.

Weeks RA and Nelson CN, 1960. Trapped electrons in irradiated quartz and silica. II. Electron Paramagnetic Resonance. Journal of the American Ceramic Society 43: 399-404.

Zhu C, Wang B and Qian W, 2008. Why do dust storms decrease in northern China concurrently with the recent global warming? $\mathrm{Ge}$ ophysical Research Letters 35(18): L18702, DOI 10.1029/2008GL034886. 